\title{
Development of a Physics-Based Design Framework for Aircraft Design using Parametric Modeling
}

\author{
Danbi Hong* and Kook Jin Park** \\ Department of Aerospace Engineering, Seoul National University, Seoul 08826, Korea
}

\author{
Seung Jo Kim*** \\ Flight Vehicle Research Center, Seoul National University, Seoul 08826, Korea
}

\begin{abstract}
Handling constantly evolving configurations of aircraft can be inefficient and frustrating to design engineers, especially true in the early design phase when many design parameters are changeable throughout trade-off studies. In this paper, a physics-based design framework using parametric modeling is introduced, which is designated as DIAMOND/AIRCRAFT and developed for structural design of transport aircraft in the conceptual and preliminary design phase. DIAMOND/AIRCRAFT can relieve the burden of labor-intensive and time-consuming configuration changes with powerful parametric modeling techniques that can manipulate ever-changing geometric parameters for external layout of design alternatives. Furthermore, the design framework is capable of generating FE model in an automated fashion based on the internal structural layout, basically a set of design parameters describing the structural members in terms of their physical properties such as location, spacing and quantities. The design framework performs structural sizing using the FE model including both primary and secondary structural levels. This physics-based approach improves the accuracy of weight estimation significantly as compared with empirical methods. In this study, combining a physics-based model with parameter modeling techniques delivers a high-fidelity design framework, remarkably expediting otherwise slow and tedious design process of the early design phase.
\end{abstract}

Key words: aircraft design framework, parametric modeling, physics-based method, structural sizing

\section{Introduction}

Aircraft design can be broken down into the following three phases; the conceptual design phase, the preliminary design phase, and the detail design phase. In the early phase of design process, various design candidates are drafted out and compared among them, eventually converging to a baseline configuration. To perform trade-off study during the early design phase shown in Fig. 1 [1], geometric models must be built using a three-dimensional CAD (Computer Aided Design) tool, and their modifications must be managed seamlessly. Hence, the concurrent engineering approach $[2,3]$ has been prevalently applied in the aerospace industry. In the concurrent engineering approach, an integrated and iterative development method has been well-established where a highly efficient design tool is indispensable to timely delivery of developed products. Similarly, to take the advantage of the Multi-Disciplinary design Optimization (MDO) [4] in the early design phase also requires an efficient design tool to begin with. From the viewpoint of the structural discipline, the automated design framework using parametric modeling techniques [5-10] can alleviate the burden of labor-intensive process to an acceptable level.

During the design process, the main interest of design engineers lies in accurately estimating aircraft weight because
This is an Open Access article distributed under the terms of the Creative Commons Attribution Non-Commercial License (http://creativecommons.org/licenses/by$\mathrm{nc} / 3.0 /$ which permits unrestricted non-commercial use, distribution, and reproduction in any medium, provided the original work is properly cited.

\footnotetext{
(c) * Ph. D Candidate, Concurrently Senior Research Engineer, Korea Aerospace Research Institute

** Ph. D Candidate

*** Professor, Department of Aerospace Engineering, Seoul National University, Corresponding author: sjkim@snu.ac.kr
} 


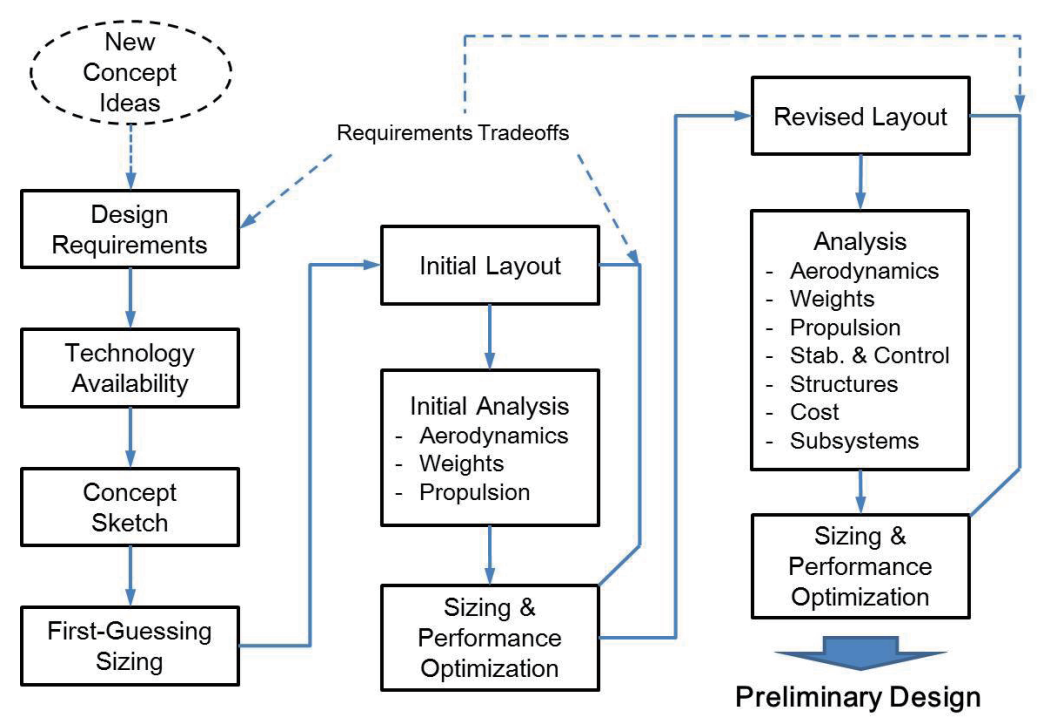

Fig. 1. Schematic Outline of Design Process in the Early Design Phase

it is a key parameter dictating performance and cost of candidate aircraft. [11-15] Therefore, one of the primary roles of design framework is to improve the level of accuracy in weight estimations as much as possible. So far, various methods of weight estimation have been proposed for aircraft design, which can be categorized into a few classes. In general, most prevalent methods generally relied on empirical approaches that process statistical database on existing aircrafts in similar size. These methods are called low class methods, which consist of Class I and Class II methods. $[16,17]$ The Class I method estimates weight of major aircraft components with the averaged figure of actual weight data from a number of existing aircrafts for the first guessing of the weight for each component. The Class II method is introduced to predict the weight of major components, in more detail than the Class I method, from semi-empirical equation or statistical data.

The Class III method is a physics-based approach that employs a high fidelity method such as finite element method (FEM). In the physics-based approach, aircraft weight is calculated based on physical properties such as volume and material density instead of relying on statistical data. With the help of high fidelity methods in the early phase, it is essential to ensure the high confidence in decision-making in that a large portion of the LCC (lifecycle cost) of aircraft is determined by decisions taken during the early design phase. [18] So the importance of using high fidelity method early in the development is being recognized with keen interest in the aerospace industry.

\section{Development of DIAMOND/AIRCRAFT}

\subsection{Motivation}

Enormous efforts have been made to construct the integrated design tool for MDO in order to solve design problems efficiently because the aircraft design is very interactive activity incorporating a number of disciplines such as aerodynamics, structure, control, and so on. $[4,6,12,18]$ With respect to parametric modeling, Mawhinney et al. [6] proposed geometry-based approach using displacement, rotation, and profile components for aircraft conceptual design to efficiently integrate the analysis and design method. But, the skeleton model for structural analysis is undesirable because the level of fidelity is unrealistic. Rodriguez et al. [7] developed RAGE (RApid Geometry Engine) in order to create the aircraft geometry for preliminary design analysis without excessively sophisticated CAD. Researchers working at NASA proposed RAM (Rapid Airplane Modeler) and VSP (Vehicle Sketch Pad) to generate 3-D geometry of aircraft quickly and easily in user-friendly environment. [5, 8] All of them, however, are not adequate to the structural design using a high fidelity method because they concentrate on generating meta-models mostly for aerodynamics or have only a limited function on structural modeling.

\subsection{The Features of DIAMOND/AIRCRAFT}

The scope of the paper presently focuses on the design framework for structural design during the conceptual and 
preliminary design phase. Hereafter, our design framework is designated as 'DIAMOND/AIRCRAFT'. The main objective of DIAMOND/AIRCRAFT is to improve the design process efficiency and accuracy through a parametric modeling and physics-based approach using FE analysis. In order to design structural components close to real ones as accurately as possible, various sizing criteria can be considered for structural sizing in DIAMOND/AIRCRAFT. The functions of the design framework are implemented in the environment of DIAMOND/IPSAP, which is the integrated FE analysis program with OpenCASCADE-based Graphic User Interface (GUI) for pre/post processing. This FE analysis program enables parallel computing process using domain-wise MFS (Multi Frontal Solver) as well as serial computing process, thus showing excellent computational efficiency for solving large-scale problem on complex aerospace structures such as aircraft, satellite, and launch vehicle. [19, 20] Hence, DIAMOND/AIRCRAFT has accordingly such a predominant heritage from DIAMOND/IPSAP.

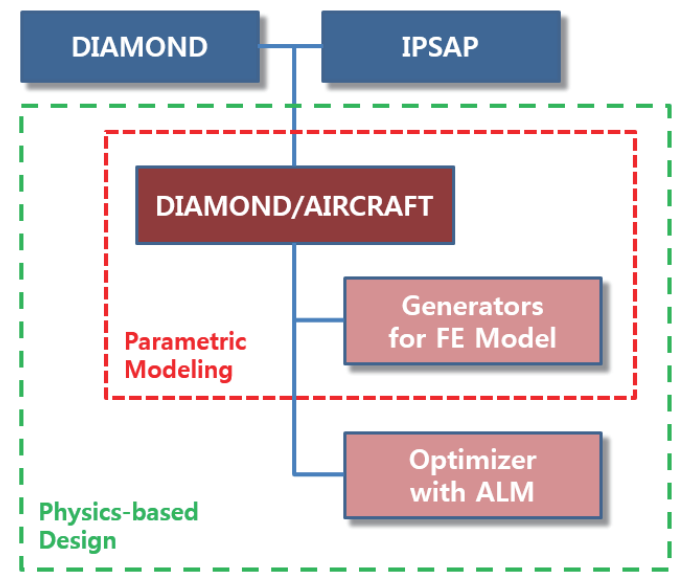

Fig. 2. Composition of DIAMOND/AIRCRAFT
Fig. 2 represents the composition of DIAMOND/AIRCARFT. In order to generate $\mathrm{FE}$ model using parametric modeling technique, DIAMOND/AIRCRAFT has three generators as follows:

(1) Wing generator

(2) Fuselage generator

(3) Empennage generator

These generators define the configuration of aircraft via manipulating simple design parameters input and at the same time generate FE model reflecting structural layout. All FE meshes from three generators can be merged to build FE model of entire aircraft. The change of FE meshes can be immediately displayed and checked as soon as design parameters change using the preview function of the design framework. Fig. 3 shows the design procedure for aircraft design using DIAMOND/AIRCARFT. In the next part, the design procedure will be described in detail.

\section{FE Model Generation via Parametric Modeling}

\subsection{Wing Generator}

First of all, airfoils selection must be performed in order to determine wing configuration. The information on geometry of three airfoils and their locations along the span-wise direction of wing are required at GUI of the wing generator. Airfoil coordinates data can be imported by text file format or be input by manual key-in.

Wing OML (Outer Mold Line) can be determined by chord lengths at root and tip of wing, semi-span, sweep back angle, airfoil data, and something about flaps. For more detailed structural layout such as the chord-wise location of front and rear spars, the number of ribs, the number

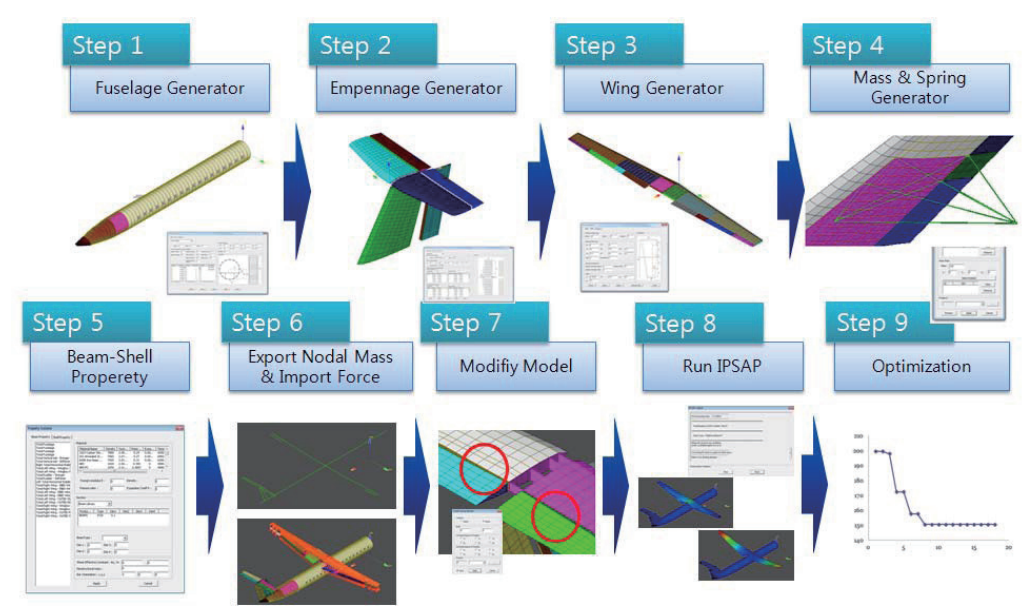

Fig. 3. Design Procedure in DIAMOND/AIRCRAFT 
of stringers, and the attachment between wingbox and secondary structures, only tens of design parameters are needed. All the design parameters on GUI can be exported for the next trial or another use in the format of text file. In DIAMOND/AIRCRAFT, the wing skins and stringers are modeled using four-node shell element and two-node beam element, respectively. The design parameters for wing configuration and structural layout are summarized in Table 1. Fig. 4 shows FE model generated for wing via parametric modeling.

\subsection{Fuselage Generator}

Just as airfoil determination is the first step for wing modeling mentioned in 3.1, so cross section definition is for fuselage modeling. As shown in Fig. 5, fuselage is divided into center fuselage, aft center fuselage, and aft fuselage for parametric modeling. In the center fuselage with constant section, two radii are required to define the cross section. In order to define structural layout of the fuselage, the number of frames and stringers, and the location of floor and its

Table 1. Design Parameters for Wing Configuration and Structural Layout

\begin{tabular}{ll}
\hline \multicolumn{1}{c}{ Purpose } & \multicolumn{1}{c}{ Design Parameters } \\
\hline & $\begin{array}{l}\text { Airfoil Coordinates and Locations } \\
\text { Chord length at Wing Root \& Tip } \\
\text { Wing Semi-Span } \\
\text { Cweepback Angle } \\
\text { Dihedral Angel } \\
\text { Location of the Flap Housing } \\
\text { Span of Inner \& Outer Flap }\end{array}$ \\
\hline \multirow{5}{*}{ Structural Layoution } & $\begin{array}{l}\text { Number of Stringers at Wing Root \& Tip } \\
\text { Location of Front \& Rear Spars for Wing } \\
\text { Location of Front \& Rear Spars for Inner \& Outer flaps }\end{array}$ \\
\hline
\end{tabular}

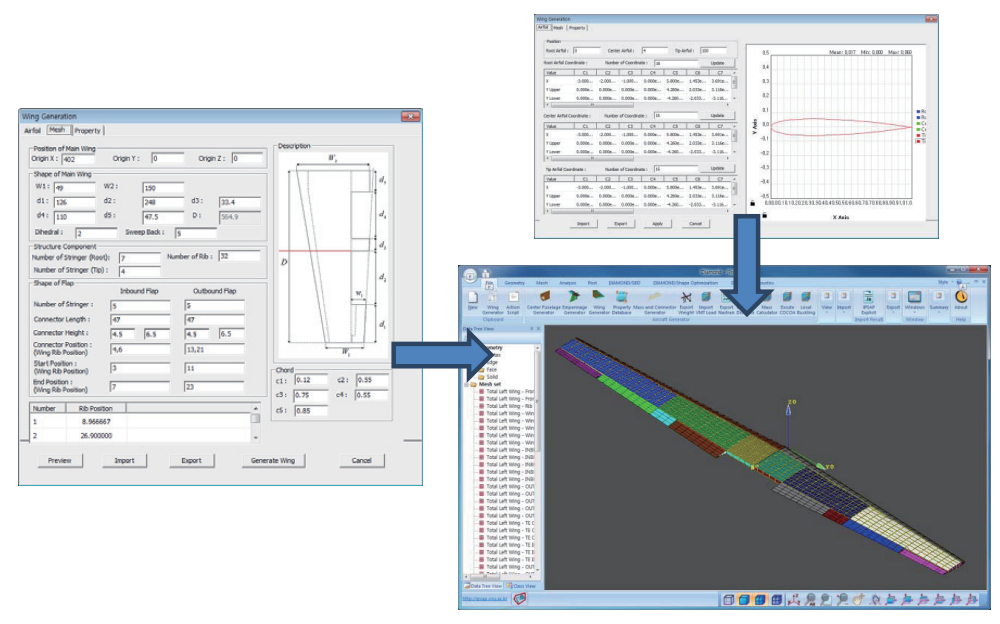

Fig. 4. FE Model Generation for Wing via Parametric Modeling

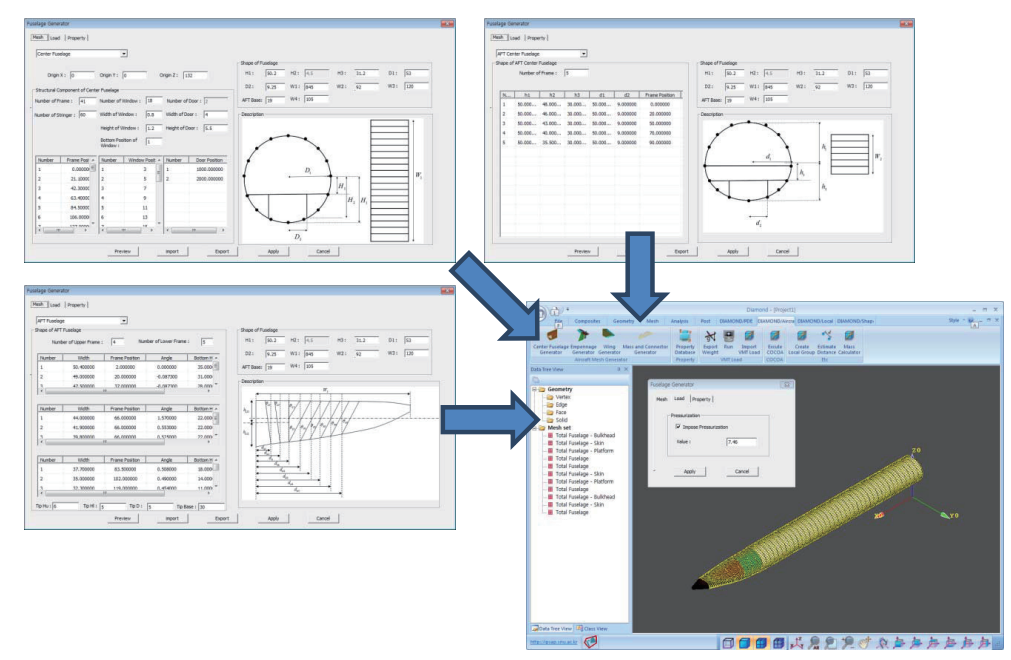

Fig. 5. FE Model Generation for Fuselage via Parametric Modeling 
supporting structures are needed. By default, all the frames are equally spaced along the length of center fuselage, but the location of each frame is promptly editable on GUI. Similarly, the location of stringers is equally spaced along the perimeter of fuselage but promptly editable if necessary. Especially for aft fuselage, the arrangement of frames must be located with a tilting angle after considering the attachment to empennage because there is a load path between fuselage and empennage. The data on window and door such as quantities and dimensions is also required for entire fuselage configuration. The design parameters for fuselage are summarized in Table 2. In DIAMOND/ AIRCRAFT, fuselage skins and stringers are modeled using four-node shell element and two-node beam element, respectively.

\subsection{Empennage Generator}

Most of the design parameters for empennage consisting of vertical and horizontal stabilizers are basically similar to those of wing. In the same manner, empennage OML is defined by three airfoil coordinates and their locations, chord lengths at root and tip, and span for both of vertical and horizontal stabilizer. With respect to structural layout, empennage can be modeled as multi-cell structure with multiple spars in order to resist external loads effectively. The design parameters for empennage configuration and structural layout are summarized in Table 3. Fig. 6 shows FE model of empennage via parametric modeling. Consequently, FE model of entire aircraft is shown in Fig. 7 including fuselage, wing, and empennage together.

Table 2. Design Parameters for Fuselage Configuration and Structural Layout

\begin{tabular}{|c|c|c|}
\hline Purpose & & Design Parameters \\
\hline \multirow{3}{*}{ Configuration } & Center & $\begin{array}{l}\text { Fuselage Length } \\
\text { Radius of Width, Radius of Height } \\
\text { Number, Location, and Dimension of Windows } \\
\text { Number \& Dimension of Doors }\end{array}$ \\
\hline & Aft Center & $\begin{array}{l}\text { Fuselage Length } \\
\text { Radius of Width, Radius of Height }\end{array}$ \\
\hline & Aft & $\begin{array}{l}\text { Fuselage Length } \\
\text { Upper Radius, Lower Radius }\end{array}$ \\
\hline \multirow{3}{*}{ Structural Layout } & Center & $\begin{array}{l}\text { Number of Frames } \\
\text { Number of Stringers } \\
\text { Location of Floor Panel } \\
\text { Location of Supporting Structure }\end{array}$ \\
\hline & Aft Center & $\begin{array}{l}\text { Number of Frames } \\
\text { Location of Floor Panel } \\
\text { Location of Supporting Structure }\end{array}$ \\
\hline & Aft & Locations and Tilt Angles of Frames \\
\hline
\end{tabular}

Table 3. Design Parameters for Empennage Configuration and Structural Layout

\begin{tabular}{|c|c|c|}
\hline Purpose & & Design Parameters \\
\hline \multirow{2}{*}{ Configuration } & HT & $\begin{array}{l}\text { Airfoil Coordinates and Locations } \\
\text { Chord length at Root \& Tip } \\
\text { Semi-Span } \\
\text { Sweepback Angle }\end{array}$ \\
\hline & VT & $\begin{array}{l}\text { Airfoil Coordinates and Locations } \\
\text { Chord Length at Root \& Tip } \\
\text { Span }\end{array}$ \\
\hline \multirow[t]{2}{*}{ Structural Layout } & HT & $\begin{array}{l}\text { Number of Stringers } \\
\text { Number of Ribs } \\
\text { Location of Interface Rib with VT } \\
\text { Gap from the Center Line }\end{array}$ \\
\hline & VT & $\begin{array}{l}\text { Number of Stringers } \\
\text { Number of Front Ribs \& Rear Ribs } \\
\text { Location and Sweepback Angle of Spars }\end{array}$ \\
\hline
\end{tabular}




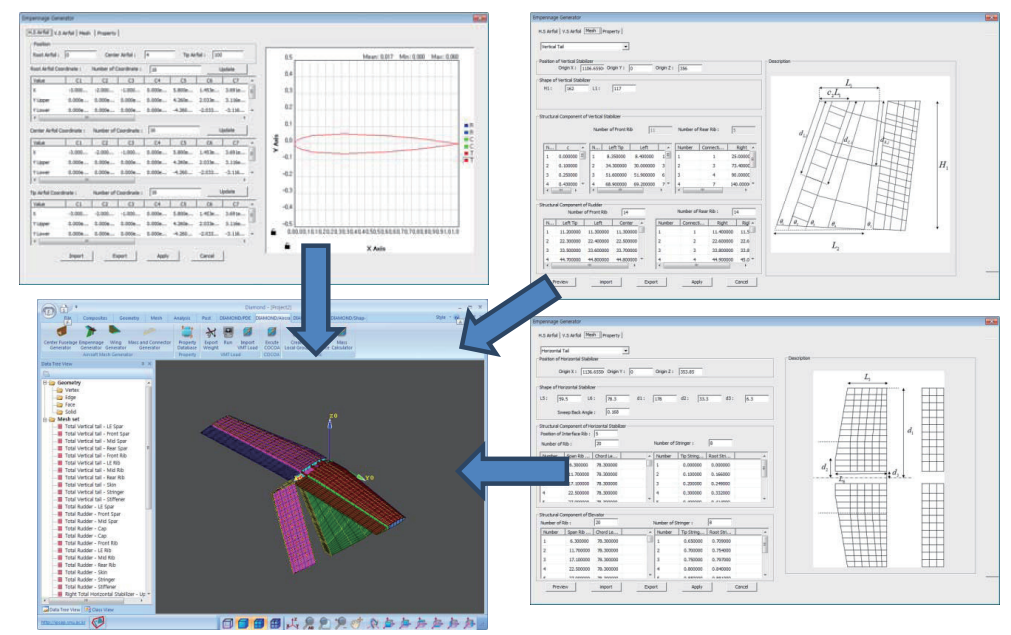

Fig. 6. FE Model Generation for Empennage via Parametric Modeling

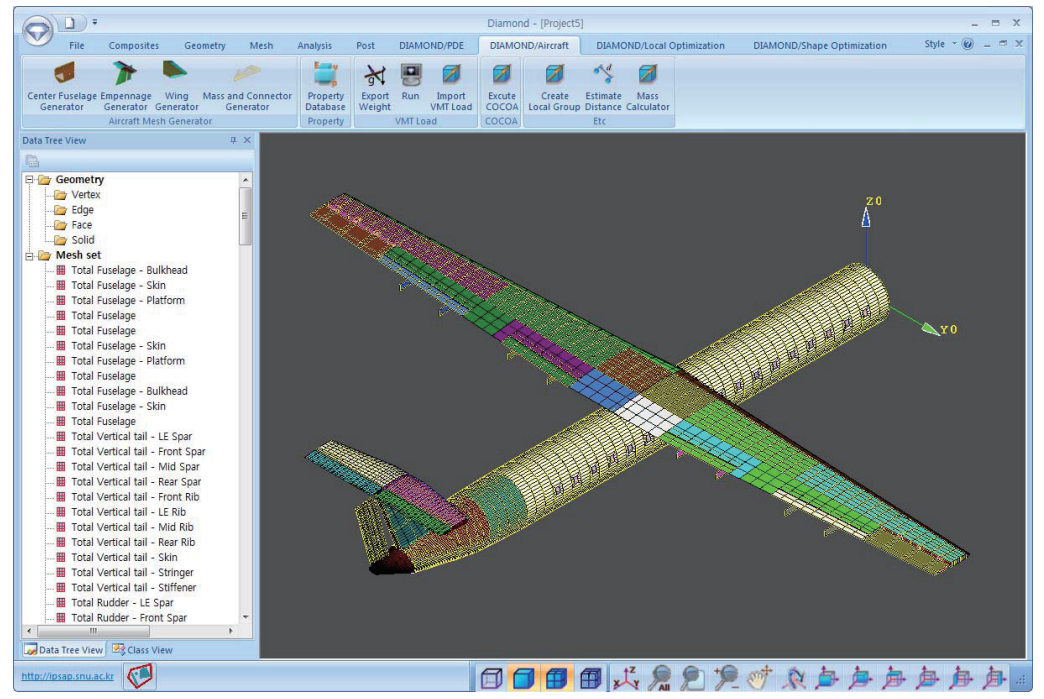

Fig. 7. FE Model Generation for Entire Aircraft via Parametric Modeling

\section{Structural Sizing for Weight Estimation}

\subsection{Load Generation}

DIAMOND/AIRCRAFT is capable of importing the result of load analysis calculated from an external program using panel method or CFD for aerodynamic analysis. The aerodynamic loads calculated in the external program can be easily imported in the form of V-M-T (shear force-momenttorsion), pressure or force distribution in DIAMOND/ AIRCRAFT. Fig. 8 shows the distribution of V-M-T loads along the load reference axis as an example. Additionally, concentrated mass can be added to simulate the inertia force from engine. When aerodynamic pressure is calculated using $\mathrm{CFD}$, the data transfer technique is required for the state variable conversion such as pressure onto the nodes of $\mathrm{FE}$ mesh because of dissimilar meshes between CFD and FEM. [21] As shown in Fig. 9, the aerodynamic load is transferred on each node of FE mesh from three nearest nodes of CFD mesh, which are found through a spatial proximity search.

\subsection{Sizing Criteria}

In DIAMOND/AIRCRAFT, various sizing criteria can be considered for structure design. The Sizing criteria play a role as constraints in the structural optimization. As sizing criteria, material strength, buckling, crippling, and user-defined formula are applicable in skin and stringer, respectively or collectively. The sizing criteria considered are summarized as shown in Table 4. [22]

For skin buckling, the coefficients including $k_{c}$ and $k_{s}$ depend on edge boundary conditions and aspect ratio. The 
curves of $k_{c}$ and $k_{s}$ are given in Fig. 10 for various aspect ratio at simply supported boundary condition. As shown in Table 4, combined buckling load condition including compression and shear loads can be also considered. Fig. 11 shows GUI for sizing criteria of beam. It is very important to consider crippling as well as buckling for stringer design. DIAMOND/AIRCRAFT can provide two methods in order to calculate crippling stress: Needham method and Gerard method. [22, 23]

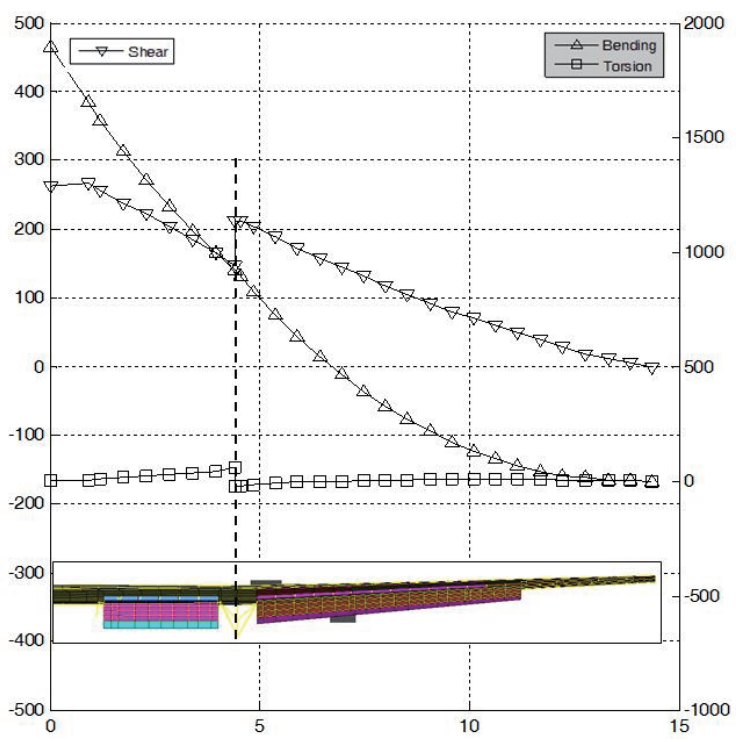

Fig. 8. Distribution of V-M-T Load along the Load Reference Axis

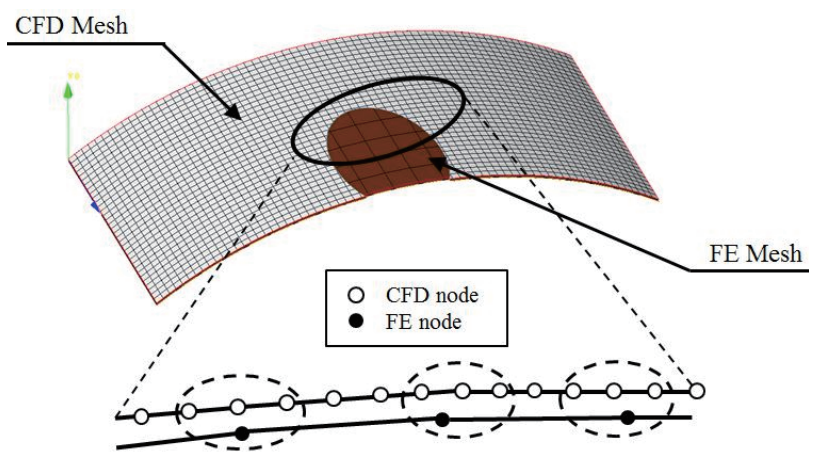

Fig. 9. Data Transfer Technique between Dissimilar Meshes

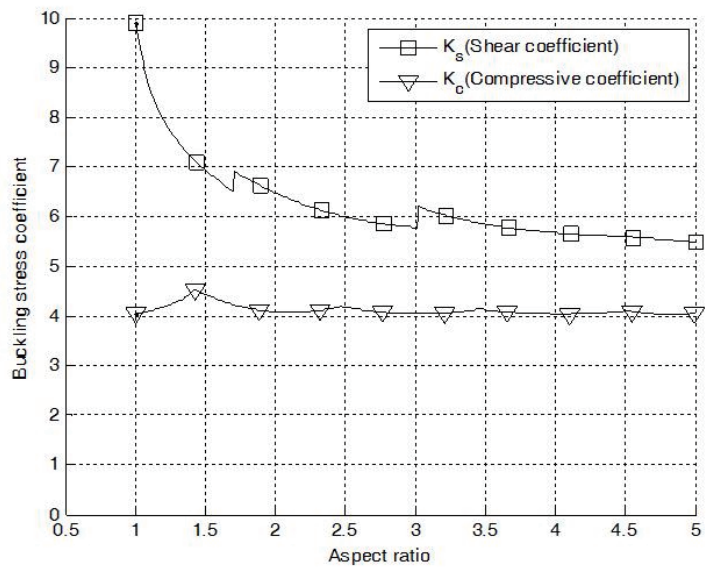

Fig. 10. Buckling Stress Coefficients for Aspect Ratio

Table 4. Sizing Criteria for Beam and Shell

\begin{tabular}{|c|c|c|c|}
\hline & & Description & Remarks \\
\hline Beam & Buckling & $F_{c}=\frac{\pi^{2} E}{\left(L^{\prime} / \rho\right)^{2}}$ & $\begin{array}{l}L^{\prime}=\text { Effective length of beam } \\
\rho=\text { Radius of gyration of cross section }\end{array}$ \\
\hline \multirow{3}{*}{$\begin{array}{c}\text { Shell } \\
\text { Buckling }\end{array}$} & Compression & $\sigma_{c r}=\frac{\pi^{2} k_{c} E}{12\left(1-v_{e}^{2}\right)}\left(\frac{t}{b}\right)^{2}$ & $\begin{array}{l}k_{c}=\text { Buckling stress coefficient } \\
b=\text { Dimension of loaded edge } \\
t=\text { Shell thickness }\end{array}$ \\
\hline & Shear & $\tau_{c r}=\frac{\pi^{2} k_{s} E}{12\left(1-v_{e}^{2}\right)}\left(\frac{t}{b}\right)^{2}$ & $\begin{array}{l}k_{s}=\text { Buckling stress coefficient } \\
b=\text { Dimension of loaded edge } \\
t=\text { Shell thickness }\end{array}$ \\
\hline & Combined & $\begin{array}{c}R_{L}+R_{S}^{2}=1.0 \\
\text { M.S. }=\frac{2}{\left(R_{L}+\sqrt{R_{L}^{2}+4 R_{S}^{2}}\right)}-1\end{array}$ & $\begin{array}{l}F_{c c r}=\text { Compressive buckling stress } \\
F_{S_{c r}}=\text { Shear buckling stress } \\
R_{L}=f_{c} / F_{c_{c r}} \\
R_{S}=f_{s} / F_{s_{c r}}\end{array}$ \\
\hline \multirow{2}{*}{$\begin{array}{c}\text { Beam } \\
\text { Crippling }\end{array}$} & $\begin{array}{l}\text { Needham } \\
\text { Method }\end{array}$ & $F_{c S} /\left(F_{c y} \mathrm{E}\right)^{\frac{1}{2}}=C_{e} /\left(b^{\prime} / t\right)^{0.75}$ & $\begin{array}{l}F_{c S}=\text { Crippling stress } \\
F_{c y}=\text { Compression yield stress } \\
\mathrm{E}=\text { Young's modulus of elasticity } \\
b^{\prime} / t=\text { Equivalent b/t of section } \\
C_{e}=\text { Coefficient that depends on the } \\
\quad \text { degree of edge support }\end{array}$ \\
\hline & $\begin{array}{l}\text { Gerard } \\
\text { Method }\end{array}$ & $F_{c s} / F_{c y}=3.2\left[\left(t^{2} / A\right)\left(E / F_{c y}\right)^{1 / 3}\right]^{0.75}$ & $\begin{array}{l}F_{c S}=\text { Crippling stress } \\
F_{c y}=\text { Compression yield stress } \\
\mathrm{E}=\text { Young's modulus of elasticity } \\
t=\text { Element Thickness } \\
\mathrm{A}=\text { Section Area } \\
* \text { applicable to } 2 \text { corner sections }(\mathrm{Z}, \mathrm{J})\end{array}$ \\
\hline
\end{tabular}




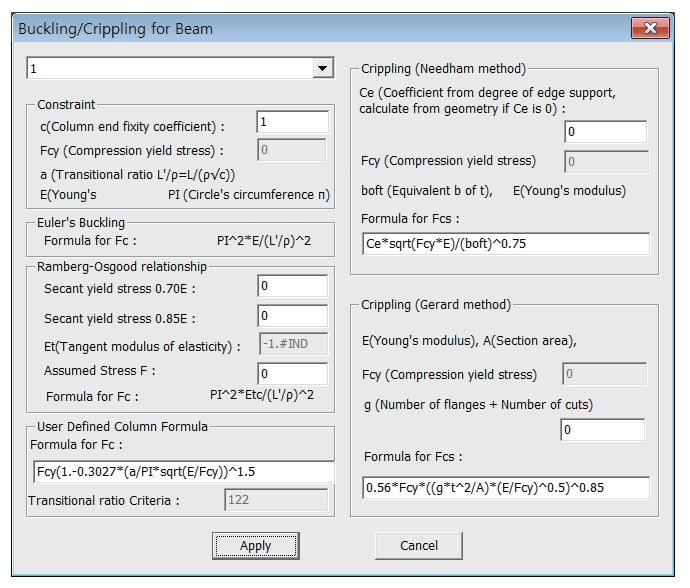

Fig. 11. Graphic User Interface for Sizing Criteria of Beam

\subsection{Comparison between Results of Weight Estimation}

When the optimization for structural sizing is completed, the weight estimation is available by multiplying the volume and the density from FE model. Besides the result from a physics-based method, DIAMOND/AIRCRAFT can also provide the weight estimation using conventional empirical methods proposed by Raymer [1], Torenbeek [24], and Corke [25]. Fig. 12 shows GUI of weight estimation module using empirical methods.

As an example for validation, the aircraft is assumed to be a 90 -seater regional turboprop with two wing-mounted engines, which has wing-mounted landing gears as well. The design variables used are thicknesses of skins and stringers, widths and heights of stringers, and thicknesses of ribs. For the sizing criteria, material strength, buckling of skin and stringers, and crippling of stringers are considered. The weight estimations of wing were calculated using three empirical methods and a physics-based method in DIAMOND/AIRCRAFT. Fig. 13 shows the stress distribution of wing skin before and after the optimization for sizing. As shown in Fig. 13, the level of stress on the wing skin becomes higher because the thickness of skin gets thinner

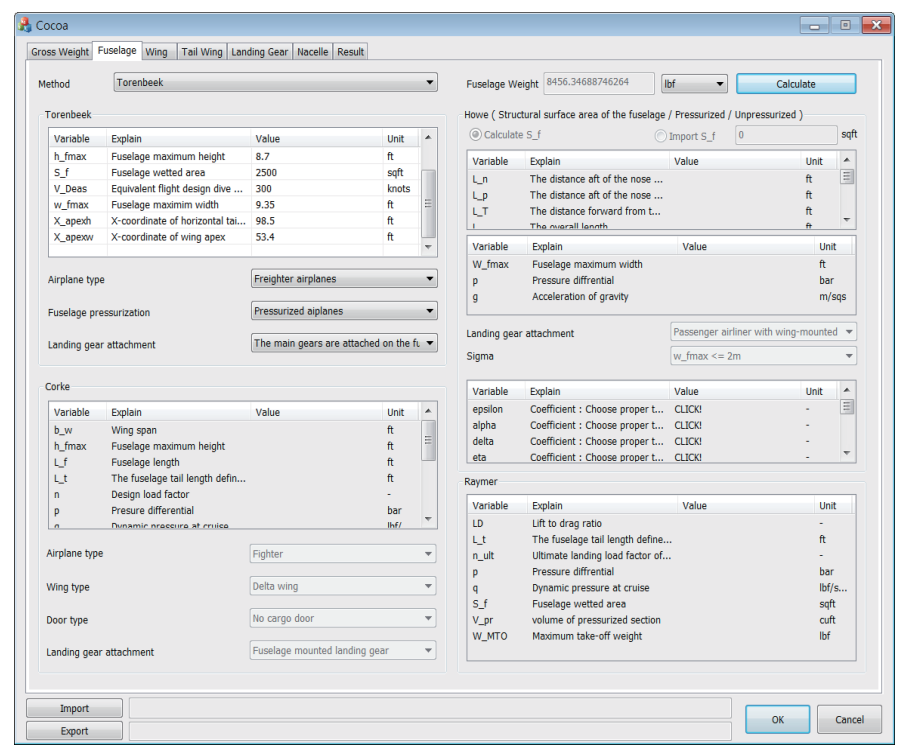

Fig. 12. Weight Estimation Module using Empirical Methods

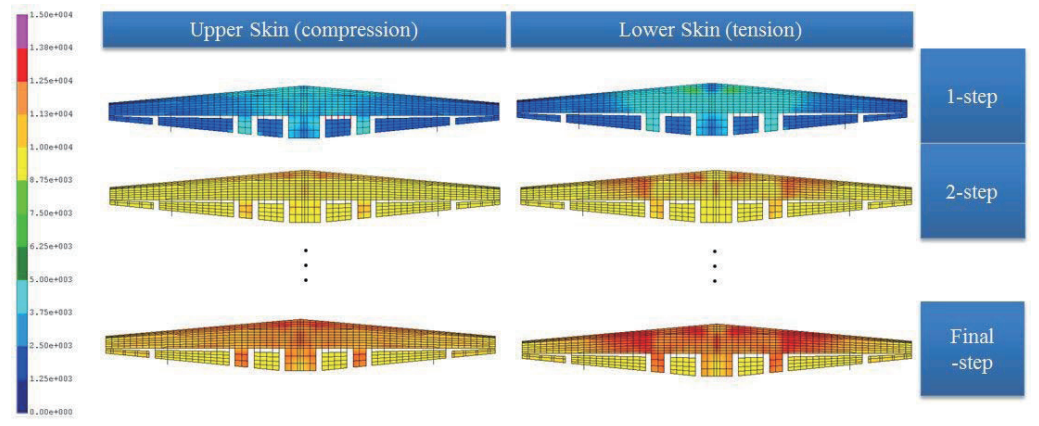

Fig. 13. Stress Distribution before and after Optimization 
Table 5. Comparison of Weight Estimations for Wing

\begin{tabular}{cccc}
\hline \multicolumn{2}{c}{ Estimation Method } & Weight (lbs) & Difference (\%) \\
\hline \multirow{2}{*}{$\begin{array}{c}\text { Empirical } \\
\text { Method }\end{array}$} & Torenbeek & 7,421 & 15.32 \\
\cline { 2 - 4 } & Raymer & 5,119 & -20.45 \\
\hline \multicolumn{2}{c}{ Corke } & 5,275 & -18.03 \\
\hline \multicolumn{2}{c}{ Physics-based Method } & 6,164 & -4.21 \\
\hline
\end{tabular}

for weight reduction as the optimization progresses. Table 5 summarizes the comparison of weight estimations of wing among applied methods. As a result, two empirical methods generally tend to underestimate the weight of wing, except the method by Torenbeek. The weight estimations using three empirical methods range from -20.45 to $15.32 \%$ difference, at least more than $15 \%$ difference, as compared with the reference weight, while the physics-based approach using DIAMOND/AIRCRAFT produces less than $5 \%$ difference. As results, it is confirmed that the weight estimation from the physics-based approach is closer to the reference weight than any other estimation by empirical methods.

\section{Conclusion and Discussion}

This paper introduces the newly developed design framework, DIAMOND/AIRCRAFT, which is applicable to the early design phase for aircraft. DIAMOND/AIRCRAFT utilized the parametric modeling technique in order to efficiently deal with the labor-intensive and iterative model updating according to design changes. DIAMOND/ AIRCRAFT can construct FE model through automated mesh generation, and the design work can be improved and facilitated with respect to the productivity.

It should be also highlighted that DIAMOND/AIRCRAFT can estimate the structural weight based on a physicsbased approach using high-fidelity method. DIAMOND/ AIRCARFT can produce the structural model considering the secondary structure as well as the primary structure, while other similar design tools can deal with the primary structure. Based on the more realistic model, the weight estimation from the physics-based method makes a good agreement with the reference weight more accurately. It is expected that the value of physics-based design framework will stand out when an unconventional advanced aircraft with no empirical weight data is developed rather than a conventional 'tube-and-wing' aircraft.

\section{Acknowledgment}

This work was supported by the Ministry of Trade, Industry and Energy, the Republic of Korea, under Core Technology Development Program for Next-generation Civil Aircraft.

\section{References}

[1] Raymer, D. P., Aircraft Design: A Conceptual Approach, 4th ed., AIAA Education Series, AIAA Inc., 2006.

[2] Sohlenius, G., "Concurrent Engineering", CIRP AnnalsManufacturing Technology, Vol. 41, Issue 2, 1992, pp. 645655.

[3] Sadraey, M. H., Aircraft Design: A Systems Engineering Approach, John Wiley and Sons, Ltd., West Sussex, UK, 2013.

[4] Sobieszczanski-Sobieski, J. and Haftka, R. T., "Multidisciplinary aerospace design optimization: survey of recent developments", Structural Optimization, Vol. 14, No. 1, 1997, pp. 1-23.

[5] Gloudemans, J. R., Davis, P. C. and Gelhausen, P. A., “A rapid geometry modeler for conceptual aircraft", Proceedings of 34th Aerospace Sciences Meeting and Exhibit, Reno, NV, 1996, pp. 1-9. DOI: 10.2514/6.1996-52

[6] Mawhinney, P., Price, M., Curran, R., Benard, E., Murphy, A. and Raghunathan, S., "Geometry-Based Approach to Analysis Integration for Aircraft Conceptual Design", Proceedings of 5th Annual Aviation Technology, Integration, and Operations (ATIO) Forum, Arlington, VA, 2005, pp. 1-9. 
DOI: DOI: 10.2514/6.2005-7481

[7] Rodriguez, D. L. and Sturdza, P., "A Rapid Geometry Engine for Preliminary Aircraft Design", Proceedings of 44th AIAA Aerospace Sciences Meeting and Exhibit, Reno, NV, 2006, pp. 1-12. DOI: 10.2514/6.2006-929

[8] Hahn, A.S., "Vehicle Sketch Pad:A Parametric Geometry Modeler for Conceptual Aircraft Design", Proceedings of 48th AIAA Aerospace Sciences Meeting, Orlando, FL, 2010, pp. 1-12. DOI: 10.2514/6.2010-657

[9] Silva, J. and Chang, K. -H., "Design Parameterization for Concurrent Design and Manufacturing of Mechanical Systems", Concurrent Engineering, Vol. 10, No. 1, 2011, pp. 3-14. DOI: 10.1106/106329302024048

[10] Amadori, K., Jouannet, C. and Krus, P., "A Framework for Aerodynamic and Structural Optimization in Conceptual Design", 25th AIAA Applied Aerodynamics Conference, 2007, pp. 25-28.

[11] Ardema, M. D., Chambers, M. C., Patron, A. P., Hahn, A. S., Miura, H. and Moore, M. D., "Analytical Fuselage and Wing Weight Estimation of Transport Aircraft", NASA Technical Memorandum 110392, 1996.

DOI: $10.4271 / 965583$

[12] Cavagna, L., Ricci, S. and Travaglini, L., "NeoCASS: an integrated tool for structural sizing, aeroelastic analysis and MDO at conceptual design level", Progress in Aerospace Sciences, Vol. 47, No. 8, 2011, pp. 621-635.

DOI: 10.1016/j.paerosci.2011.08.006

[13] Elham, A., La Rocca, G. and Van Tooren, M. J. L., "Development and implementation of an advanced, designsensitive method for wing weight estimation", Aerospace Science and Technology, Vol.29, 2013, pp. 100-113.

DOI: 10.1016/j.ast.2013.01.012

[14] Bindolino, G., Ghiringhelli, G., Ricci, S. and Terraneo, M., "Multilevel Structural Optimization for Preliminary Wing-Box Weight Estimation", Journal of Aircraft, Vol.47, No.2, 2010, pp. 475-489.
DOI: $10.2514 / 1.41552$

[15] Chen, B., Luo, M., Shen, Z., Wu, Z., Man, Y. and Fang, L., "Wing weight estimation considering constraints of structural strength and stiffness in aircraft conceptual design", International Journal of Aeronautical and Space Science, Vol. 15, No. 4, 2014, pp. 383-395.

DOI: 10.5139/IJASS.2014.15.4.183

[16] Roskam, J., Airplane Design, DAR Corporation, Kansas, 2003.

[17] Torenbeek, E., Advanced Aircraft Design, John Wiley and Sons, Ltd., West Sussex, UK, 2013.

[18] Rizzi, A., "Modeling and simulating aircraft stability and control-The SimSAC project", Progress in Aerospace Sciences, Vol. 47, 2011, pp. 573-588.

DOI: 10.1016/j.paerosci.2011.08.004

[19] Kim, S. J., Moon, J. K. and Kim, M. K., "Capabilities and Performance of General Purpose Parallel Finite Element Program, DIAMOND/IPSAP", Proceeding of Tri-University Workshop on Aero-Structural Mechanics \& Aerospace Engineering (NASPC/TUWMA2008), Beijing, China, 2008.

[20] Kim, J. H., Lee, C. S. and Kim, S. J., "High-Performance Domainwise Parallel Direct Solver for Large-Scale Structural Analysis", AIAA Journal, Vol. 43, No. 3, 2005, pp.662-670.

DOI: $10.2514 / 1.11171$

[21] Samareh, J. A., "Discrete data transfer technique for fluid-structure interaction", 18th AIAA Computational Fluid Dynamics Conference, AIAA 2007-4309, 2007, pp.1-12.

DOI: 10.2514/6.2007-4309

[22] Bruhn, E. F., Analysis and Design of Flight Vehicle Structures, Tri-State Offset Company, 1973.

[23] Niu, M. C.-Y., Airframe Stress Analysis and Sizing, Conmilit Press Ltd., Hong Kong, 1997.

[24] Torenbeek, E., Synthesis of Subsonic Airplane Design, Kluwer Academic Publishers, Dordrecht, The Netherlands, 1982.

[25] Corke, T. C., Design of Aircraft, Prentice Hall, 2003. 